\title{
CLINICAL EVALUATION OF REMOVABLE PARTIAL DENTURE CONSTRUCTED FROM 3D PRINTED RESIN PATTERN DESIGNED USING CAD CAM TECHNOLOGY
}

\author{
Ahmed S Saad ${ }^{1} B D S$, Faten S Abbas ${ }^{2} P h D$, Safyah H Elgharabawy² $P h D$
}

\begin{abstract}
INTRODUCTION: Computer-assisted design, computer-assisted manufacture (CAD/CAM) can be successfully applied to the fabrication of removable partial denture (RPD) alloy frameworks and replace laboratory crafting techniques. The CAD/CAM techniques have been widely used for a long time to manufacture dental prostheses. Computer-aided technologies allow more precise and systematic modeling, and could therefore reduce the burdensome steps of both chair-side and laboratory work, saving vital time.

OBJECTIVES: This study was aimed to compare between the accuracy of chrome-cobalt removable partial denture frameworks designed and fabricated using CAD/CAM technique with that fabricated using conventional technique

MATERIALS AND METHODS: Seven maxillary bilateral partially edentulous patients having Class III modification 1 Kennedy classification were selected from those attended to the prosthodontic department, Faculty of Dentistry, Alexandria University. For each patient, two different cobalt chromium removable partial frameworks were constructed; the first one was fabricated using CAD CAM technique (group A)and the other framework was fabricated using conventional manufacturing technique(group B) and were compared through evaluation of: (1) Guiding plane/plate relation. (2) Accuracy of fit of occlusal rests and major connector.

RESULTS: all removable partial dentures fabricated by CAD/CAM technology showed increased improvement of accurate adaptation of the palatal strap major connector, guiding planelplate relation and fit of occlusal rest, also it was less time consuming and economic need compared to conventional technique.

CONCLUSIONS: The use of CAD/CAM technology for fabrication of removable partial denture frameworks should be widely applied because of its favorable clinical accuracy.

KEYWORDS: Removable partial denture, CAD/CAM, Guiding planes, Chrome-Cobalt powder, Occlusal rests adaptation.
\end{abstract}

1-B.D.S. Prosthodontics Department, Faculty of Dentistry, Alexandria University, Alexandria, Egypt

2-Professor of Prosthodontics Department, Faculty of Dentistry, Alexandria University, Alexandria Egypt

Corresponding author:

E-mail: dentist_129@hotmail.com

\section{INTRODUCTION}

The past decade has witnessed a growing interest in digital image technologies and model reproduction by electronic means. These technologies paved the way towards a significant advancement of the modeling and manufacture of dental replacements by introducing modern Computer Aided (CA) systems, state-of-the-art materials and machining technologies, as opposed to the conventional ways of manual manufacture which are prone to numerous subjective errors $(1,2)$.

In dentistry, CAD/CAM technologies have been applied in the field of prosthodontics ever since the 1980s. Nowadays these are also being extensively used in maxillofacial technology and surgery (3-5).

There has been a rapid increase in the employment of Computer-aided design (CAD) and Computer-aided manufacture (CAM) technologies in dental application instead of conventional RPD frameworks which are manufactured through what is called Lost Wax Technique avoiding errors of conventional technique (6-8).

Computer-aided technologies allow more precise and systematic modeling, and could therefore reduce the burdensome steps of both chair-side and laboratory work, saving vital time. More specifically, the application of CAD/CAM technologies were restricted to restorative dentistry and fixed prosthodontics, but in the last few years many studies have been introduced to apply these technologies in the field of removable prosthodontics (8).

CAD CAM technologies help in reducing time of the laboratory steps by about $60-70 \%$ as there is no need for refractory model and no need for manual waxing up of the framework also the CAD software makes automatic surveying and block out of the undercuts, in addition it is easy and not expensive (9).

\section{MATERIALS AND METHODS}

This study reviewed and accepted by committee of ethical scientific research, Faculty of dentistry, Alexandria University. The clinical study was explained to the patients and they accept it and an informed consent was signed by all them. Seven maxillary bilateral partially edentulous patients having Class III modification 1 Kennedy classification were selected from those attended to the prosthodontic department, Faculty of Dentistry, Alexandria University.

For each patient, two different cobalt chromium removable partial denture frameworks were constructed; the first one was fabricated using CAD/CAM technique (group A) and the other framework was fabricated using conventional manufacturing technique (group B) and comparing them through evaluation of: 
1- Guiding plane/plate relation.

2-Accuracy of fit of occlusal rests and major connector.

The Removable partial denture frameworks were fabricated as follow:

A preliminary impression was recorded for each patient using irreversible hydrocolloid impression material (Cavex CA37 (normal set), Holland BV, Haarlem). It was poured to get study cast and a custom tray was fabricated using auto polymerized acrylic resin material.

Fabrication of cobalt chromium removable partial denture framework using CAD/ CAM technique (group A)

The study cast was scanned using digital dental scanner (3 shape TRIOS D700 digital scanner (3Shape, A/S Holmens Kanal, 7 DK-1060, Copenhagen K) to get a preliminary virtual model.

A digital preliminary surveying was done using auto surveying function and design outline was done on the virtual model.

A suggested mouth preparation chart was filled, and essential mouth preparations were made according to the selected design.

Following all intraoral mouth preparations, final impressions were recorded using auto polymerized acrylic custom trays with a condensation type of polyvinyl siloxane impression material. (Zhermack INC. 45021 Badia,Polesine,Rovigo Italy).

Then all final impressions were poured using fast set extra-hard type IV dental stone (Kimberlit, Protechno, Ginora, Spain) to get the master casts.

All master casts were scanned using Digital Scanner (3 shape D900 digital scanner3shape) to produce a virtual 3D master model.

RPD designing software(3Shape) was used to design RPD frameworks (figure 1).

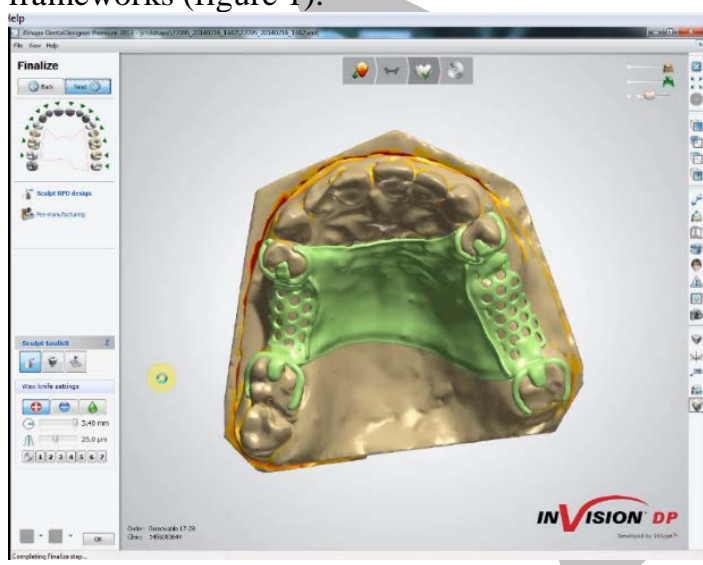

Figure 1: $\mathrm{CAD}$ frameworks.

Spruing and investing of 3D Printed wax patterns (figure 2).

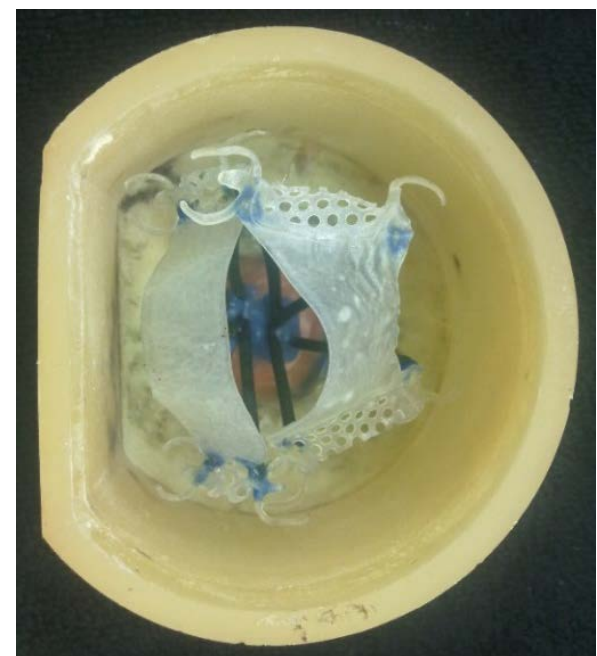

Figure 2: Investing 3D printed framework.

Casting, Finishing and Polishing were done using conventional technique.

All frameworks were tried in intra orally (figure 3).

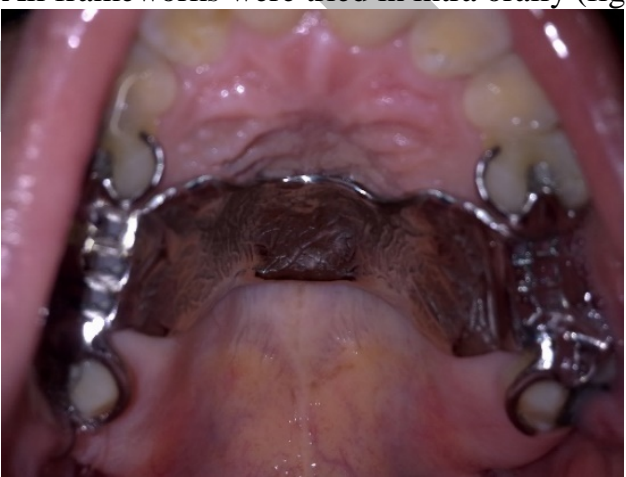

Figure 3: Clinical try in.

Fabrication of cobalt chromium removable partial framework using conventional technique (Group B):

After scanning the master casts for the CAD/CAM technique, they were prepared and duplicated using agaragar reversible hydrocolloid duplicating material 1 (Sheraduble, Shera GmbH \& Co. KG, Lemförde, Germany) then use investment material (Bego, Bremer Herbst GmbH Co, Germany) to produce the refractory casts.

The same designs of group A frameworks were made for frameworks of group B.

The wax patterns were fabricated using preformed casting wax sheets on the working refractory casts.

The wax patterns were sprued, invested, casted, finished and polished. The frameworks were seated to the master casts then tried clinically.

\section{Methods of evaluation}

All frameworks were clinically evaluated as regard the following criteria:

1) The guiding plate/plane relation (10):

Each finished removable partial framework was tried inside the patient's mouth and the areas of interference between guiding plane of the abutment teeth and the related guiding plate of the framework were evaluated using occlusion spray (Bausch Arti-Spray, Germany). It was sprayed on the fitting surface of guiding plates, then framework was seated with firm finger pressure at the occlusal rests. The presence or absence of interference 
between guiding plane and guiding plate was evaluated as follows:

Score (0): means absence of any interference where there was no show through in the occlusion indicating material at the guiding plate.

Score (1): presence of slight interference. Where there was minimal show through of the occlusion indicating material.

Score (2): presence of heavy interference where there was total show through of the occlusion indicating material.

2) The adaptation of the major connector (11):

The fit of each major connector was measured by using auto polymerizing fast set acrylic resin material (figure 4) (Dura lay) (Duralay, Reliance Dental Mfg. Co., Worth, Illinois, USA). The indexed points were placed at the following locations:

L1: Middle upper point; at mid palatal point of anterior border of major connector, $0.5 \mathrm{~cm}$ below the beading line.

L2: Middle lower point; at mid palatal point of posterior border of major connector, $0.5 \mathrm{~cm}$ above the beading line.

L3: At left lateral side, $0.5 \mathrm{~cm}$ medial to the internal finish line.

L4: At right lateral side $0.5 \mathrm{~cm}$ medial to the internal finish line.

L5: Midway between L1 and L2 at the center.

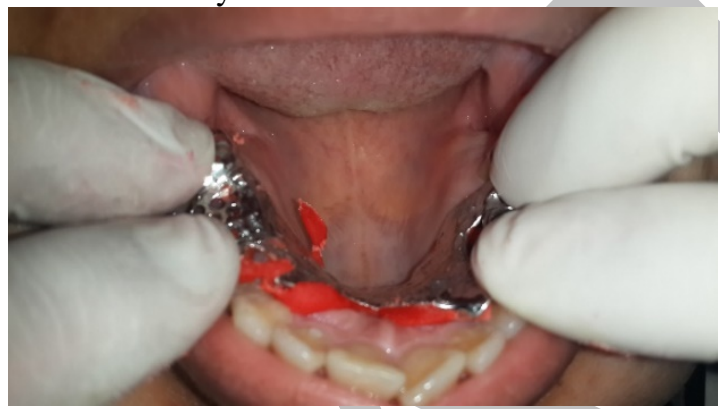

Figure 4: Framework fitted with duralay

The recorded thickness for each point was measured and recorded using micrometer caliper (SHANGAHEN 025 mm CHINA micrometer caliper).

3) The occlusal rest /rest seat relation (12):

Fit of occlusal rest of each occlusal rest was evaluated as described by Dunham et al (12) using vinyl polysiloxane (VPS) material. The VPS was injected to the fitting surface of the occlusal rest. The removable partial framework was firmly inserted intraorally with sufficient finger pressure to fully seat the prosthesis. After the VPS material had polymerized, the RPD framework was removed for inspection. Areas of tooth-metal contact were identified and recorded on a customized data collection form. The occlusal rest was divided into 2 zones (central and peripheral) (Figure 5).

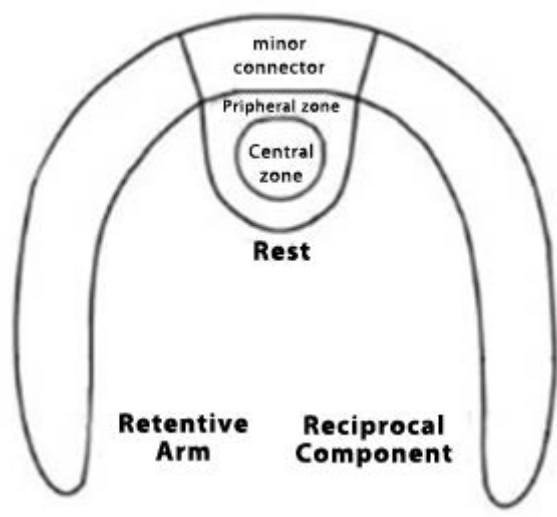

Figure 5: Central and peripheral zones of the occlusal rest. Statistical analysis

The data were collected, tabulated and statistically analyzed. Mean standard deviation and median were calculated. The distributions of quantitative variables were tested for normality using Kolmogorov-Smirnov test, Shapiro-Wilk test and D'Agstino test, also Histogram and QQ plot were used for vision test (13). For normally distributed data, comparison between two independent populations was done using independent t-test. For abnormally distributed data or ordinal data, comparison between two independent populations were done using Mann Whitney test. To compare between the different groups, Wilcoxon signed ranks test was applied. Significance of the obtained results was judged at the $5 \%$ level.

\section{RESULTS}

\section{1) Guiding plate /plane relation:}

By comparing between the studied groups regarding guiding plane/plate relation at both molars and premolars, there was a statistically significant difference between both groups with ( $\mathrm{p} 1$ value $<0.001$ and $=0.001$ ) respectively, indicating that frameworks of group A showed reduced guiding plane /plate interference (Table 1).

Table 1: Comparison of guiding plane/plate relationship between the two studied groups at all the abutments of both right and left sides.

\begin{tabular}{|l|l|l|l|l||}
\hline $\begin{array}{l}\text { Reference } \\
\text { points }\end{array}$ & $\begin{array}{l}\text { CAD-CAM } \\
\text { technique } \\
\text { (group A) } \\
\text { (n= 7) }\end{array}$ & $\begin{array}{l}\text { Conventional } \\
\text { Technique } \\
\text { (group } \\
\text { (n= 7) }\end{array}$ & B) & T \\
\hline L1 & $0.27-0.39$ & $0.33-0.59$ & P & \\
$\begin{array}{l}\text { Min.- Max. } \\
\text { Mean } \pm \text { SD. } \\
\text { Median }\end{array}$ & $0.31 \pm 0.04$ & $0.41 \pm 0.09$ & 2.827 & $0.015^{*}$ \\
\hline L2 & 0.32 & 0.39 & & \\
$\begin{array}{l}\text { Min. - Max. } \\
\text { Mean } \pm \text { SD. }\end{array}$ & $0.22-0.47$ & $0.34-0.57$ & & \\
Median & $0.32 \pm 0.08$ & $0.42 \pm 0.08$ & 2.392 & $0.034^{*}$ \\
\hline L3 & 0.30 & 0.39 & & \\
Min. - Max. & $0.28-0.32$ & $0.30-0.39$ & & $0.035^{*}$ \\
Mean \pm SD. & $0.30 \pm 0.01$ & $0.34 \pm 0.04$ & 2.595 & \\
Median & 0.29 & 0.32 & & \\
\hline L4 & & & & \\
Min. - Max. & $0.21-0.30$ & $0.29-0.38$ & & \\
Mean \pm SD. & $0.27 \pm 0.03$ & $0.32 \pm 0.04$ & 2.962 & $0.012^{*}$ \\
Median & 0.27 & 0.31 & & \\
\hline L5 & & & & \\
\hline
\end{tabular}




\begin{tabular}{||l|l|l|l|l||} 
Min. - Max. & $0.28-0.39$ & $0.37-0.63$ & & \\
Mean \pm SD. & $0.33 \pm 0.4$ & $0.45 \pm 0.09$ & 3.250 & $0.007^{*}$ \\
Median & 0.33 & 0.40 & & \\
\hline L Average & & & & \\
Min. - Max. & $0.26-0.37$ & $0.34-0.51$ & & \\
Mean \pm SD. & $0.30 \pm 0.04$ & $0.39 \pm 0.06$ & 3.163 & $0.008^{*}$ \\
Median & 0.30 & 0.37 & & \\
\hline
\end{tabular}

t: Student t-test

*: Statistically significant at $\mathrm{p} \leq 0.05$

\section{2) The adaptation of the major connector:}

Table (2) and Figure (6) show the comparison of the duralay thicknesses for the palatal strap major connector between the two studied groups (A and B) at five different reference points.

Table 2: Comparison between the two studied groups according to the duralay layer thicknesses of the palatal strap at different reference points of the major connector.

\begin{tabular}{|c|c|c|c|c||}
\hline & \multicolumn{4}{|c|}{ Central zone } \\
\hline Technique & \multicolumn{2}{|c|}{$\begin{array}{c}\text { CAD-CAM } \\
\text { technique (group } \\
\text { A) } \\
(\mathbf{n = 2 8 )}\end{array}$} & $\begin{array}{c}\text { Conventional } \\
\text { Technique (group B) } \\
\text { (n = 28) }\end{array}$ \\
\hline Score & No. & \% & No. & \% \\
\hline 0 & 18 & 64.3 & 12 & 42.9 \\
1 & 10 & 35.7 & 14 & 50.0 \\
\hline 2 & 0 & 0.0 & 2 & 7.1 \\
\hline $\mathbf{Z}$ & & \multicolumn{5}{|c||}{0.079} \\
\hline $\mathbf{P}$ & \multicolumn{5}{|c|}{0.758} \\
\hline
\end{tabular}

Z: Z for Mann Whitney test for comparison between group A and group B

*: Statistically significant at $\mathrm{p} \leq 0.05$

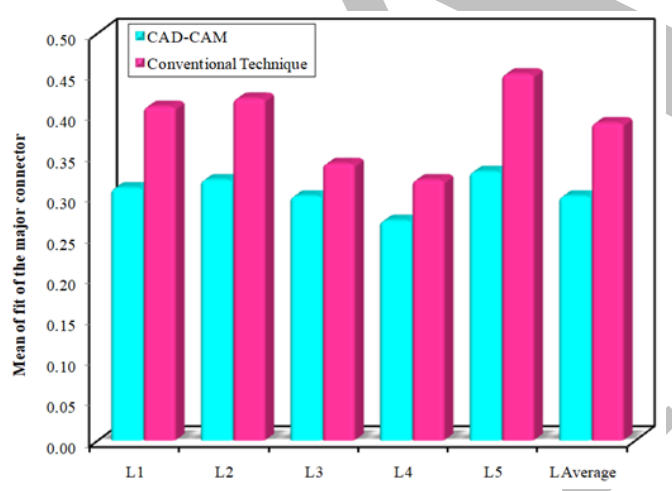

Figure 6: Comparison between the two studied groups according to the duralay layer thicknesses at different reference points of the major connector

According to the reference point L1 there was statistically significant difference between the two groups with $P$ value of 0.015 .

There was statistical significant difference between the two groups for L2 with $\mathrm{P}$ value of 0.034 indicating more fit of palatal major connector among (group A).

There was statistical significant difference between the two groups for L3 with $\mathrm{P}$ value of 0.035 indicating more fit of palatal major connector among (group A).
There was statistical significant difference between the two groups for L4 with P value of 0.012 .

According to reference point L5 there was no statistically significant difference between the two groups with $P$ value of 0.007 .

Also by comparing the average of all reference points of group A with mean $(0.30+0.04)$ with average reference points of group $B$ there was no statistically significant difference between both groups with $P$ value of 0.008 .

3- Fit of occlusal rests (occlusal rest/rest seat relationship):

It was found that there were no significant statistical differences in the results comparing between the two groups for central zone $(\mathrm{P}=0.079)$ table (3).

For peripheral zones of the occlusal rests there was significant difference between the two groups $(\mathrm{P}=0.034)$ table (3).

Table 3: Comparison between the two studied groups according to the fit of occlusal rests (peripheral zone and central zone) for all abutments.

\begin{tabular}{|c|c|c|c|c||}
\hline & \multicolumn{4}{|c|}{ Peripheral zone } \\
\hline & \multicolumn{2}{|c|}{$\begin{array}{c}\text { CAD-CAM } \\
\text { technique (group A) } \\
(\mathbf{n}=\mathbf{2 8})\end{array}$} & $\begin{array}{c}\text { Conventional Technique } \\
\text { (group B) } \\
(\mathbf{n}=\mathbf{2 8})\end{array}$ \\
\hline Score & No. & $\%$ & No. & \% \\
\hline 0 & 18 & 64.3 & 10 & 35.7 \\
\hline 1 & 10 & 35.7 & 18 & 64.3 \\
\hline 2 & 0 & 0.0 & 0 & 0.0 \\
\hline $\mathbf{Z}$ & & & 2.119 \\
\hline $\mathbf{P}$ & & \multicolumn{5}{|c|}{$0.034^{*}$} \\
\hline
\end{tabular}

Z: Z for Mann Whitney test

*: Statistically significant at $\mathrm{p} \leq 0.05$

\section{DISCUSSION}

Clinical experience with cast Co-Cr alloy RPDs showed that a framework seldom fits the mouth accurately without the need for some adjustments (14-16).

This misfit may be attributed to the fact that RPDs frameworks are fabricated from high shrinkage alloys and the complexity of the work stages used in the RPD $(17,18)$. Computer-aided technologies allow more precise and systematic modeling, and could therefore reduce the burdensome steps of both chair-side and laboratory work, saving vital time.

This study was conducted to evaluate the accuracy of using CAD/CAM technology in the fabrication of cobalt chromium removable partial denture by comparing the fit of the frameworks fabricated using CAD/CAM technique with those fabricated using conventional technique.

Each palatal strap was selected to be clinically evaluated as it is the area of removable partial denture framework where inaccuracy mostly detected on the master cast and inside the patient's mouth as reported in several researches $(19,20)$.

For every patient, two different frameworks were fabricated, one constructed by the CAD CAM technique (group A) and the other one fabricated by conventional technique (group B). 
All studied frameworks were fabricated by using cobalt chromium alloy because it is the conventional alloy to be used for removable partial denture construction for its multiple favorable characteristics as reported by Careck et al (21) who stated that cobalt chromium dental alloys are widely used by clinicians because of their good mechanical properties and corrosion resistance $(22,23)$. Good mechanical properties of these alloys are the result of multiphase structure, age hardening among alloy components and precipitation of carbides which substantially increase their hardness $(24,25)$.

The guiding plane / plate relation was clinically evaluated to detect the presence or absence of interferences between them during RPD framework fitting inside the patient's mouth. The contact indicating spray (Occlude) was selected because it is easily used, offers minimal thickness, adheres well to the metallic framework, cannot be washed away by excessive saliva, and easily removed from the framework by alcohol (26).

The fit of major connector was evaluated by measuring the space between the major connector and the palatal mucosa at different reference points as reduced space indicates more accurate fit. Auto polymerized fast set acrylic resin material (Duralay) with the help of micrometer caliper was used to measure this space because the duralay material has a fine grain size that offers fast set, sufficient flow, superior accuracy and rigidity in thin sections that does not distort when being measured with a micrometer caliper (27).

The fit of each studied occlusal rest to its occlusal rest seat was measured by using vinyl polysiloxane (VPS) as described by Parker et al (28) and was confirmed by Dunham et al (17) to be an accurate method to measure the minute space between occlusal rest and its rest seat due to its high flowability.

The advantages of polyvinyl siloxanes are that they are easy to remove from the framework, provide a threedimensional perspective, and have minimal thickness (29).

The results obtained from this study showed that all cobalt chromium RPD frameworks fabricated by both the conventional and CAD/CAM technique revealed slight interference between the guiding plane and its guiding plate, occlusal rest to its rest seat as well as reduced misfit of all major connectors but the frameworks fabricated by CAD/ CAM technique revealed more significant reduced interference and minute misfit.

Regarding the degree of interference of the guiding plane/plate relation, there was significant difference between the two studied groups (A\& B) at both premolars and molars. There was noticed increase in the degree of interference in the molars (42.9\% for group A and $85.7 \%$ for group B) than premolars (28.6\% for group A and 71.4 $\%$ for group B) which may be attributed to the increased surface of contact between the guiding plate and guiding plane of molars as reported by another investigator who discussed the fitting of RPD frameworks fabricated using light cure wax frameworks and found that interferences at molar abutments were more apparent than interferences at premolars (30).

Readings obtained from clinical evaluation of guiding plane plate relationship revealed less interference with removable partial denture frameworks fabricated using CAD CAM technique with percentage of $35.7 \%$ with slight interference(score 1) and none of the frameworks showed heavy interference (score 2) which indicated more accurate fit and this accuracy can be attributed to the minimal laboratory procedures required for CAD CAM technique because most of the laboratory errors of conventional technique produces inaccurate frameworks as stated by many investigators $(31,32)$ who reported many laboratory errors affecting RPD accuracy.

The other attribution for the apparent accurate fit of frameworks fabricated by CAD CAM technique was related to the use of $3 \mathrm{D}$ printed wax which had high mechanical and physical properties resulting in more accurate fit as reported by few studies which found that the use of CAD CAM technology improves the accuracy of RPD framework due to high mechanical and physical properties of the 3D printed wax and minimal laboratory procedures $(33,34)$.

On the reverse the pliable and soft nature of casting wax used for conventional technique, in addition to its high ductility, strongly suggests that dimensional changes related to its manipulation should be expected (34). Moreover, some studies have shown that the amount of induced stresses and the subsequent distortions of the wax patterns are influenced by storage time, position, and dimensions of the wax patterns (35).

As regard to the accuracy of the fit of the metal palatal strap against the palate of the master cast and the mouth, it was found that in every RPD framework, there seemed to be a gap between the palatal major connector and the palate, ranging from $0.09 \mathrm{~mm}$ to $0.68 \mathrm{~mm}$ on the cast and from 0.11 to $0.93 \mathrm{~mm}$ in the mouth (16).

When comparing the results of the groups (A and $\mathrm{B}$ ), regarding the fit of the major connector; It was found that there were statistical significant differences between the two groups by evaluating the thickness of the duralay layer among frameworks fabricated using CAD CAM technique indicating reduced thickness and consequently more fit than that fabricated using conventional technique. This may be due to the same previous attribution of the accurate fit of guiding plate. Also, the minimal laboratory procedure required for CAD CAM technique reveal less dimensional changes.

It was demonstrated that the highest discrepancies in fit of the major connector of all frameworks were located at the center of each framework which was demonstrated by slight increase of the thickness of the dura lay at L5 reference point. This conclusion can be proved by the results of Diwan et al (27) who stated that discrepancies in fit increases toward the center of the palate. This conclusion can be attributed to the release of stresses by the effect of time, and variations in thermal contractions in different portions of the framework as observed by Eeirkäinen E and Rantanen $\mathrm{T}$ (14) who observed tendencies of the framework to contract in certain portions more than others, such as towards the center of the palate and attributed this to the variations in thermal expansion in different portions of the framework.

At the opposite side, the metal frameworks fabricated by conventional technique showed inaccuracies in the fit of the palatal major connector and other components on the master cast and inside the patient mouth which had been reported in several researches $(14,19,20)$.

There was a statistically significant difference among the two studied groups as regard the fit of the peripheral zone of the occlusal rests for all abutments when compared 
with central zone which may be attributed to that metal shrinkage occurs towards the center of the occlusal rest as reported by Stern et al (36). This result coincides with results obtained by other study which found that peripheral zone of the occlusal rests shows more fit than central zone (29).

At the same time, some studies reported that spaces were found between the vertical wall and the deepest portion of the respective rest seat on the master cast (14). Stern et al (36) found that the rests fabricated by conventional technique of mandibular class I and II RPD fit significantly better than those mandibular class III and IV.

It was found by several studies that one fifth of occlusal rests didn't contact the opposing rest seat at any point (36). Also, most of the occlusal rests (76\%) which were evaluated by Dunhman et al (17) didn't contact the intended surfaces.

But our study revealed apparent accurate occlusal rest fit of frameworks fabricated by CAD/CAM technique when compared with that fabricated by conventional technique.

There was a significant difference between the two studied groups according to the fit of the peripheral zone of the occlusal rests indicating more fit of removable partial frameworks fabricated using CAD/CAM technique which also can be attributed to limitation of laboratory steps by using CAD/CAM technology.

The fit of RPD framework at the guiding plane, occlusal rest, palatal major connector using vinyl polysiloxan, occlude spray was previously reported by different studies (30). Other methods were also used as reported by Robert J Williams (37) who evaluated the fit of RPD using x-ray and ultrasonic waves.

The more accurate fit of different components of RPD frameworks fabricated by CAD/CAM technique can also be attributed to the limitation of the use of finishing tools on the internal surface of the framework which was not needed because of the perfect tissue surface of those frameworks. Using the finishing tools during the finishing procedures of frameworks fabricated by conventional technique was previously reported to increase the errors affecting the accuracy of the RPD frameworks components $(17,25)$.

The same results of improved accuracy of PRD frameworks fabricated by CAD/ CAM technique was reported by other investigators as Williams et al (38) who stated that the RPD framework produced using the SLM process in conjunction with cobalt-chrome alloy resulted in an RPD framework that is comparable in terms of accuracy, quality of fit, and function to those produced by existing methods commonly used in dentistry.

Also, Tamrakar et al (39) conclude that CAD/CAM systems, though costly in the initial phase, however the accuracy and the quality of restoration outweighs its economic factor and undoubtedly the future of prosthodontics will be led by these CAD/CAM technologies.

Aeran et al (40) concluded that the advancements in the CAD/CAM systems have developed not only from the structural level but, also at the level of precision and applications.

In general, the results of this study advocated the use of CAD/CAM technology in fabrication of removable partial denture frameworks for its improvement of adaptation of the palatal strap major connector, guiding planelplate relation and fit of occlusal rest. Also, it is less time consuming, economic and need less efforts.

This accurate fit of RPD frameworks fabricated using $\mathrm{CAD} / \mathrm{CAM}$ technology will give favorable effect on the health of the oral tissues.

\section{CONCLUSION}

1. The guiding plane/plate relationship of the frameworks fabricated using CAD/CAM technology showed significant reduced interference when compared with those fabricated by conventional technique.

2. There was significant reduced thickness of duralay material at the palatal strap major connector of the frameworks fabricated using CAD/CAM technique which indicated more accurate fit when compared with those fabricated using conventional technique.

3. There was significant reduction of the thickness of the duralay layer at the center of the palatal major connector of the frameworks fabricated using CAD/CAM technology when compared with those fabricated using conventional technique which was referred as (L5) reference point where the highest discrepancies in fit of the palatal major connector can occur

4. The fit of the occlusal rests for all studied abutments was statistically significant indicating more accuracy of removable partial denture frameworks fabricated using CAD/CAM technique when compared with those fabricated using conventional technique.

5. The peripheral zone of the occlusal rests showed significant reduction of the scores of vinyl polysiloxan than that of central zone of the occlusal rests of all frameworks indicating more fit of peripheral zone than that of central zone of occlusal rests.

6. In general, there was more accurate fit of the components of the frameworks fabricated by CAD/CAM technique compared with that fabricated by conventional technique.

\section{CONFLICT OF INTEREST}

The authors declare that they have no conflicts of interest.

\section{REFERENCES}

1- Azari A, Nikzad S. The evaluation of rapid prototyping in dentistry: a review. Rapid Prototype J. 2009; 15:216-25.

2- Miyazaki T, Hotta Y, Kunii J, Kuriama S, Tamaki Y. A review of dental CAD/CAM current status and future perspectives from 20 years of experience. Dent Mater J. 2009; 28:44-56.

3- Williams RJ, Bibb R, Eggbeer D, Collis J. Use of CAD/CAM technology to fabricate a removable partial denture framework. J Prosthet Dent. 2006; 96:96-9.

4- Hughes CW, Page K, Bibb R, Taylor J, Revington P. The custom-made titanium orbital floor prosthesis in reconstruction for orbital floor fractures. $\mathrm{Br}$ Oral Maxillofacial Surg. 2003; 41:50-3.

5- Kanazawa M, Inokoshi M, Minakuchi S, Ohbayashi N. Trial of a CAD/CAM system for fabricating complete dentures. Dent Mater J. 2011; 30:93-6.

6- Rantanen T, Eerikanien E. Accuracy of the palatal plate of removable partial dentures, and influence of laboratory 
handling of the investment on accuracy. Dent Mater. 1986:2:28-31.

7-Firtell DN, Muncheryon AM, Green AJ. Laboratory accuracy in casting removable partial denture frameworks. Prothet Dent. 1985; 54:856-62.

8-Bars by MJ, Schward WD. The qualitative assessment of Cobalt-Chromium Casting for partial dentures. Br Dent J. 1989; 166:211-6.

9-Miyazaki T, Hotta Y, Kunii J, Kuriyama S, Tamaki Y. A review of dental CAD/CAM: current status and future perspectives from 20 years of experience. Dent Mater J. 2009; 28:44-56.

10- Craig RG, Antony DH, Peyton FA. Dimensional changes in duplicating investment casts. Dent Prog 1961; 2: 39.

11- Hindles GW. Stress analysis on distal extension partial dentures. J Prosthet Dent 1957; 7: 197.

12- Dunham D, Brudvik JS, Morris J, Plummer KD, Cameron SM. A clinical investigation of the fit of removable partial prosthesis clasp assemblies. J Prosthet Dent. 2006; 95:3236.

13- Kirkpatrick LA, Feeney BC. A simple guide to IBM SPSS statistics for version 20.0. Student ed. Belmont, Calif.: Wadsworth, Cengage Learning, 2013.

14- Eeirkäinen E, Rantanen T. Inaccuracies and defects in frameworks for removable partial dentures. J Oral Rehabil. 1986; 13:347-53.

15- Ali M, Narin RI, Sherriff M, Waters NE. The distortion of cast cobalt chromium alloy partial denture frameworks fitted to a working cast. J Prosthet Dent. 1997; 78:419-24.

16- Schwartz IS. A review of methods and techniques to improve the fit of cast restorations. J Prosthet Dent. 1986; 56:279-83.

17- Dunham D, Brudvik JS, Morris J, Plummer KD, Cameron SM. A clinical investigation of the fit of removable partial prosthesis clasp assemblies. J Prosthet Dent. 2006; 95:3236.

18- Bortun CM, Sandu L, Porojan S. Using of light-curing waxes in the removable partial denture technology. Int Poster J Dent Oral Med. 2007; 9:371.

19- Juszczyk AS, Likeman PR. A laboratory study of the fit of cast cingulum rests. Quintessence Dent Technol. 1995; 18:133-41.

20- Barby MJ, Schwarz WD. The qualitative assessment of cobalt chromium castings for partial dentures. Br Dent J. 1989; 166:211-6.

21- Carek A, Zivko-Babic J, Schauperl Z. Microstructure analysis of base alloys joints. MED, Dublin, Ireland. 2006;340-9.

22- Stojcevic I, Carek A, Bukovic D, HeSever M. Influence of the partial denture on the articulation of dental and postalveolar Sounds. Collegium Antropologicum. 2004; 28:799-807.

23- Carek A, Zivko-Babic J, Schauperl Z, Jakovav M. Mechanical properties of Co-Cr welded alloy. J Dent Res. 2010; 89:745.
24- Zvko-Babic J, Jerolimov V. Metals in dental prosthodontics. Zagreb: Skolska knjiga; 2005.

25- Horvat ALM, Zvko-Babic J, Ivankovic D, Babic S, Kastelan- Macan M. Anodic sampling and TLC identification of dental alloys. J Planar Chromatogr. 2001; 14:426-9.

26- Dukes BS, Fields H Jr. Comparison of disclosing media used for adjustment of RPD frameworks. J Prosthet Dent. 1981; 45:380-2.

27- Diwan R, Talic Y, Omar N, Sadig W. The effect of storage time of removable partial denture wax pattern on the accuracy of fit of the cast framework. J Prosthet Dent. 1997; 77:375-81.

28- Parker MH, Cameron SM, Hughbanks JC, Reid DE. Comparison of occlusal contacts in maximum intercuspation for two impression techniques. J Prosthet Dent. 1997; 78:255-9.

29- Sato Y, Sato M. Use of a silicone disclosing material in patients with embrasure undercuts. J Prosthet Dent. 2001; 86:135-6.

30- Samy O. Evaluation of the effect of using free standing resin pattern technique, compared to conventional wax pattern technique, on the dimensional accuracy of cobaltchromium removable partial. M.Sc. Thesis. Faculty of Dentistry, Alexandria University. 2008.

31- Rudd RW, Rudd KD. A review of 243 errors possible during the fabrication of a removable: Part I. J Prosthet Dent. 2001; 86:251-61.

32- Rudd RW, Rudd KD. A review of 243 errors possible during the fabrication of a removable: Part II. J Prosthet Dent. 2001; 86:262-76.

33- Eggbeer D, Bibb R, Williams R. The computer-aided design and rapid prototyping fabrication of removable partial denture frameworks. Proc Inst Mech Eng H 2005; 219:195-202.

34- Available at: http://www.Envisiontech .com

35- Hutton JE, Marshall GW. The expansion of phosphatebonded investments: part I-setting expansion, J Prosthet Dent. 1993; 70:121-5.

36- Stern MA, Brudvik JS, Frank RP. Clinical evaluation of removable partial denture rest seat adaptation. J Prosthet Dent. 1985; 53:658-62.

37- Williams RJ, Rafik T, Al-Hourani Z. An electronic method for measuring the fit of removable partial denture frameworks to dental casts. J Eng Res. 2009; 6:15-20.

38- Williams RJ, Bibb R, Rafik T. A technique for fabricating patterns for removable partial denture frameworks using digitized casts and electronic surveying. J Prosthet Dent. 2004; 91:85-8.

39- Tamrakar AK, Rathee M, Mallick R, Dabas S. CAD/CAM in prosthodontics - a futuristic overview. A DS; 2014; 2:14-6.

40-Aeran H, Kumar V, Seth J, Sharma A. Computer aided designing-computer aided milling in prosthodontics: a promising technology for future. Case Report \& Reviews. IJSS. 2014; 1:23-7. 